\title{
Intuition and Conscious Reasoning
}

\author{
Ole Koksvik* \\ (Forthcoming in The Philosophical Quarterly.)
}

\begin{abstract}
This paper argues that, contrary to common opinion, intuition can result from conscious reasoning. It also discusses why this matters.
\end{abstract}

\section{Introduction}

Can having an intuition justify belief? That depends, in all likelihood, on what intuitions are. If intuitions are like emotions the answer is probably 'no', since emotions do not in general justify belief in their content. If intuitions are relevantly similar to perceptual experiences, on the other hand, the answer is more likely 'yes', since perceptual experiences generally do. Those who care about the epistemology of intuitions should therefore also care about their nature.

Before counting a mental state as an intuition, many thinkers place restrictions on the state's causal history. There are two broad types of such restrictions: the state must either have a particular history, or it must lack one. A common positive etiological restriction is that the state must derive

*Many thanks to David Chalmers, Daniel Korman, Leon Leontyev, Daniel Nolan, Joel Pust and Weng Hong Tang for helpful discussion. 
"from one's understanding of one's concepts". ${ }^{1}$ A very widely accepted negative etiological restriction is that the state must fail to result from conscious reasoning. ${ }^{2}$

I argue that this second restriction should be rejected: contrary to popular opinion, intuition can result from conscious reasoning. I then show why this matters.

\section{Aims and Approach}

It may be worth noting that I do not aim to partake in-or start-a quarrel about how we should use the word 'intuition'. I take this to be a merely verbal dispute ${ }^{3}$ which we would do well to avoid.

The interesting questions are whether there is a class of mental states which constitutes a good candidate for a psychological kind-a kind which cuts the mind at its natural joints-and which deserves the label 'intuition' well enough. If such a class exists it is furthermore interesting to ask what its characteristics are. My aim here is to help answer questions such as these, and not to argue over semantics.

\footnotetext{
${ }^{1}$ George Bealer, "The Origins of Modal Error", Dialectica 58 (2004), pp. 11-42, at p. 13; George Bealer, "Intuition and Modal Error", Epistemology: New Essays, ed. by Quentin Smith, Oxford University Press, 2008, at p. 191; see also Paul A. Boghossian, "Virtuous Intuitions: Comments on Lecture 3 of Ernest Sosa's A Virtue Epistemology", Philosophical Studies 144 (2009), pp. 111-119, p. 119; and Laurence BonJour, In Defence of Pure Reason, Cambridge University Press, 1998, at p. 101.

${ }^{2}$ See, for example, Paul A. Boghossian, "Inference and Insight", Philosophy and Phenomenological Research 63 (2001), pp. 633-640, at p. 636; Laurence Jonathan Cohen, The Dialogue of Reason, Clarendon Press, 1986, at pp. 75-6; Alison Gopnik and Eric Schwitzgebel, "Whose Concepts Are They, Anyway? The Role of Philosophical Intuition in Empirical Psychology", Rethinking Intuition, ed. by Michael DePaul and William Ramsey, Rowman \& Littlefield, 1998, at p. 77; Michael Lynch, "Trusting Intuition", Truth and Realism, ed. by Patrick Greenough and Michael P. Lynch, Oxford University Press, 2006; Alvin Plantinga, Warrant and Proper Function, Oxford University Press, 1993, at p. 106; Joel Pust, Intuition as Evidence, Garland Publishing, 2000, at pp. 44-5; but compare Michael Huemer, Ethical Intuitionism, Palgrave Macmillian, 2005, at p. 101. See also Herman Cappelen, Philosophy Without Intuitions, Oxford University Press, 2012, at pp. 33, 46.

${ }^{3}$ David Chalmers, "Verbal Disputes", The Philosophical Review 120 (2011), pp. 515-566.
} 
How might one support the claim that there is a psychological kind which deserves to be called 'intuition' and which can result from conscious reasoning? Well, either by arguing that we have reason to believe that there is a nearby psychological kind which isn't subject to this etiological requirement, or by arguing that lack reason to believe that there is a nearby psychological kind which is.

The former task might be carried out by providing a positive characterisation of a class of mental states without making reference to etiology. If the class deserves the label 'intuition' well enough, and if the members share important and interesting features-perhaps they can play a certain epistemological role, for example-the claim has been defended. Elsewhere I have attempted to provide just such a characterisation, but it is, I confess, quite long. ${ }^{4}$ Here I will therefore go the other route, and attempt to support the claim that we lack reason to think that there is a nearby class of mental states which cannot result from conscious reasoning and which constitutes a psychological kind.

\section{Intuitions Can Result from Conscious Reasoning}

To fix ideas, suppose you adopted the view that intuitions are experiences of a certain kind, such that when one has the intuition that $p$ it seems to one that $p$, and that simply having an intuition provides some justification to believe what it represents. (This is my view.) Should you think that intuitions in this sense can result from conscious reasoning?

It is true, of course, that one can come to believe a proposition $p$ by reasoning one's way to $p$, and that this needn't involve its coming to seem to one that $p$ : one might believe that certain premises are true and that $p$ follows from those premises, for example. ${ }^{5}$ But why should we think that

\footnotetext{
${ }^{4}$ Ole Koksvik, "Intuition", PhD thesis, The Australian National University, 2011. Available from www. koksvik. net.

${ }^{5}$ See for example George Bealer, "The Incoherence of Empiricism", Proceedings of the
} 
a process of conscious inference with $p$ as its conclusion cannot result in it seeming to the agent that $p$ ? If the task of interest is to delineate a good candidate for a psychological kind there seems to be no reason to require from the outset that conscious argument be absent.

In fact, such a requirement seems ad hoc. Even those who restrict their attention to what they call 'rational' or 'philosophical' intuition do not ban antecedent conscious deliberation about the concepts involved in $p$ immediately before the intuition arises. For example, no one thinks there should be a ban on thinking about the logical connectives before having the intuition that one of de Morgan's laws holds. And it would be absurd to hold that one cannot think about the law itself just before having the intuition. As Bealer points out, it is most often precisely when you consider these things that the law suddenly seems true to you (1992, p. 101). It is very hard to see what reason one might have to allow the deliberation that goes on beforehand to take any form whatever, except only the particular form of an argument. Contrary to common opinion, then, the clear presumption should be that the negative etiological restriction does not apply to intuition. We need an argument to deviate from this stance.

Joel Pust has recently presented just such an argument: ${ }^{6}$

[U]nless intuitions are non-inferential they cannot serve ... as the ultimate premises in philosophical argumentation and analysis. Philosophical practice treats intuitions as basic, as not admitting of further inferential support, and this provides us with a reason for requiring of any genuine intuition that it not be the result of conscious inference.

Similarly, L. Jonathan Cohen, to whom Pust attributes this argument, ar-

Aristotelian Society, Supplementary Volume 66 (1992), pp. 99-138, at p. 102. It is a separate and interesting question whether one must have an intuition corresponding to each transition in a proof or argument, as Locke arguably thought; see An Essay Concerning Human Understanding $\S \S 4.2 .1-4.2 .7$.

${ }^{6}$ Pust no longer defends this argument. 
gues that "[i]f intuition is to provide the ultimate premises of philosophical argument, those premises should not themselves be the conclusions of further reasoning" (p. 76). And it is reasonable to assume that the very widespread acceptance of the negative etiological requirement is largely due to sympathy with similar reasoning.

I want to make two comments about this argument. First, Cohen and Pust are concerned in particular with philosophical intuition. Given that project, perhaps it makes sense to limit the candidates according to the role intuition is thought to play in theory construction. If, however, the interest is in delineating a good candidate for a psychological kind this is getting things the wrong way around: we first need to delineate a kind, and then see what work it can do in philosophy.

But second, let us distinguish two senses of being 'non-inferential'. In one sense, $\mathrm{S}^{\prime} \mathrm{s}$ intuition that $p$ is non-inferential if it is not the result ofin the sense of being caused by-conscious deliberation. In another, the intuition is non-inferential just in case S's justification to believe that $p$ after having the intuition does not wholly rest on the support $p$ receives in virtue of being the conclusion of an argument.

To provide foundational justification, it is clear that intuition must be non-inferential in the second sense. But why think it must be noninferential in the first sense? I can think of no other reason than the belief that the two do not come apart.

But in fact, clearly they do. To see this, imagine that I do not grasp de Morgan's laws, and that you set out to explain them to me:

Assume that it is not the case that $p$-and- $q$, which is to say that $p$-and- $q$ is false. One way for that to happen is if $p$ is false. In that case, $p$ and $q$ are obviously not both true (we just said that $p$ is false). And if $p$ and $q$ are not both true, $p$-and- $q$ is false. So one way for $p$-and- $q$ to be false is for $p$ to be false.

Naturally, another way to get the same result is for $q$ to be false 
instead: the reasoning is just the same. And a third way is if $p$ and $q$ are both false. But if $p$-and- $q$ is false, one of these three things has to to be the case: either $p$ is false, or $q$ is false, or both $p$ and $q$ are false. There is no other way.

Now, not-p-or-not- $q$ is true in exactly those three situations; when either one of $p$ and $q$ is false, or both $p$ and $q$ are false. So, you see, if it's not the case that $p$-and- $q$, then it is the case that not-p-or-not-q.

This may not be the snappiest of arguments. But it is an argument. It is valid, and it yields one direction of one of de Morgan's laws as its conclusion. In a similar fashion, you could have explained the other direction to me. But it is surely at least possible that at the end of such explanations it comes to seem to me that the transformation in question is valid. After all, that seems to be the point of the entire affair!

Had I been a little quicker I might have arrived at the point where I could 'just see' that the transformation holds simply by staring at $\neg(p \& q) \leftrightarrow(\neg p \vee \neg q)$ for a while. But my being able to 'just see' that the transformation holds can just as much be the result of your patient explanation (along with that of the other direction), a result of your arguing that it does, and my following along in a conscious reasoning process. In such a circumstance, why should the value of my being able to just see this depend on what took place just before?

If I really do just see it, my justification for believing the transformation does not rest wholly on the support this receives in virtue of being the conclusion of an argument. It rests in part on the fact that I just see it to be so, that I have the intuition that it is so.

So: while a proposition which is the conclusion of an argument does not have foundational justification if it is justified only because it follows from premises that are also justified, it is no bar to its having foundational 
justification in virtue of being the content of an intuition that what allows, prompts, or causes the intuition to arise is a conscious reasoning process. On the view of intuition mentioned above, for example, the question is simply whether the right kind of experience obtains. If it does, what brought this about is irrelevant. The same is true for other views. (Perhaps knowledge about what brought about the experience in some cases defeats the justification, as, for example, Peter Singer ${ }^{7}$ thinks is the case for moral intuitions, but that is a separate matter.)

Some might try to save the negative etiological requirement by claiming that two processes are at work here, one conscious reasoning process, on the one hand, and another separate, non-conscious process on the other, and that I count as having an intuition because my 'just seeing' that the transformation holds is in part caused by the non-conscious process. (I am grateful to an anonymous referee for raising this objection.)

We should acknowledge that there are such cases. But there are surely also cases where the sole cause of my being able to 'just see' that the transformation holds is the conscious reasoning process. Stipulating that the case discussed above is one of these, the argument loses none of its force: it is just as plausible as before that, because it really does seem to me that the transformation holds, its so seeming provides me with foundational justification for that belief.

To sum up: a restriction that intuition may not be the result of conscious reasoning is, in the absence of argument, ad hoc. The argument that without the restriction, intuition cannot provide foundational justification, fails. Absent further argument we therefore lack reason to think that there is a class of mental states which deserves the label 'intuition', which constitutes a psychological kind, but which cannot result from conscious reasoning.

\footnotetext{
${ }^{7}$ Peter Singer, "Ethichs and Intuitions", The Journal of Ethics 9 (2005), pp. 331-352.
} 


\section{Why It Matters}

Why does any of this matter? For at least four reasons.

Most obviously, realising that intuition can result from conscious reasoning teaches us something about its nature, and provides a constraint on theory. Someone who wishes to account for the nature of intuition must also consider the intuitions which result from conscious reasoning, and must ensure that her theory can capture these cases.

Second, the reasoning which shows that intuitions can result from reasoning also teaches us something about the structure of justification. A conclusion, one might have thought, cannot provide foundational justification. Not so, if what I have argued is correct: it can, albeit not in virtue of being a conclusion.

Third, when a proposition $c$ is the conclusion of an argument with premises $p_{1}, \ldots, p_{n}$, it is usually thought that $c$ cannot support further conclusions $d, e, \ldots$, independently of $p_{1}, \ldots, p_{n}$. That is, if the argument is deductive and no other arguments support the conclusion, and bracketing the possibility of a high prior credence in $c$, ones rational credence in the most plausible of $p_{1}, \ldots, p_{n}$ sets the upper bound for rational credence both in $c$, and in $d, e, \ldots$. But if what I have argued is correct, this is not in general true. In each case we have to ask whether $c$ is supported solely because it follows from $p_{1}, \ldots, p_{n}$, or whether it is justified also because it seems true to the agent. In the former case, one's justification for $c, d$, and $e$ cannot exceed the justification for the most plausible of $p_{1}, \ldots, p_{n}$ (holding the assumptions fixed). But in the latter case it can. Suppose, for example, that you have determined that a deductive argument from $p_{1}, \ldots, p_{n}$ to $c$ supports a credence in the latter of .7, and that no other argument you know of supports $c$. If you also have the intuition that $c$-prompted, perhaps, precisely by the conscious reasoning process of going through the argument-it may now be rational for you to have credence .85 in $c$, since the intuition provides additional justification. 
Finally, the realisation that intuition can result from conscious reasoning suggests a possible reply to the experimental philosophy challenge to the use of intuition in philosophy. Broadly speaking, the challenge is that intuitions vary in ways that indicate, it is claimed, that they cannot be reliable guides to truth. ${ }^{8}$

If the above is correct, some intuitions result from conscious reasoning and some do not. If, as seems likely, philosophers to a significant extent use intuitions of the former type, and if, as I think is the case, the experimental philosophy movement has almost exclusively probed those that do not, the movement misses its target to that extent, because (in a slogan) what they test is not what we use. It then remains possible that intuitions that result from conscious reasoning are reliable guides to truth, even if some of those that do not are not.

\footnotetext{
${ }^{8}$ See, for example, Jonathan M. Weinberg, Shaun Nichols, and Stephen Stich, "Normativity and Epistemic Intuitions", Philosophical Topics 29 (2001), pp. 429-460.
} 